\title{
ILDE: Community Environment for Conceptualizing, Authoring and Deploying Learning Activities
}

\author{
Davinia Hernández-Leo ${ }^{1}$, Juan I. Asensio-Pérez ${ }^{2}$, Michael Derntl $^{3}$, \\ Luis P. Prieto ${ }^{4}$, Jonathan Chacón ${ }^{1}$ \\ ${ }^{1}$ ICT Department, Universitat Pompeu Fabra, Barcelona, Spain \\ \{davinia.hernandez, jonathan.chacon\} @upf.edu \\ ${ }^{2}$ School of Telecommunication Engineering, Universidad de Valladolid, Spain \\ juaaseetel.uva.es \\ ${ }^{3}$ Advanced Community Information Systems (ACIS), RWTH Aachen University, Germany \\ derntl@dbis.rwth-aachen.de \\ ${ }^{4}$ École Polytechnique Federale de Lausanne (EPFL), Switzerland \\ luis.prietodepfl.ch
}

\begin{abstract}
This demonstration paper presents the Integrated Learning Design Environment (ILDE). ILDE is being developed in the METIS project, which aims at promoting the adoption of learning design by providing integrated support to teachers throughout the whole design and implementation process (or lifecycle). ILDE integrates existing free- and open-source tools that include: codesign support for teacher communities; learning design editors following different authoring and pedagogical approaches; interface for deployment of designs on mainstream Virtual Learning Environments (VLEs). The integration is designed so that teachers experience a continuous flow while completing the tasks involved in the learning design lifecycle, even when the tasks are supported by different tools. ILDE uses the LdShake platform to provide social networking features and to manage the integrated access to designs and tooling including conceptualization tools (OULDI templates), editors (WebCollage, OpenGLM), and deployment into VLEs (e.g., Moodle) via GLUE!-PS.
\end{abstract}

Keywords: learning design, integrated environment, teacher communities, authoring, deploying

\section{Introduction: Meeting teachers' co-design needs}

The METIS project ("Meeting teachers' co-design needs by integrated learning environments"; www.metis-project.org) aims at providing a complete set of conceptual and technological tools capable of supporting teachers along the whole process of going from pedagogical intentions to the setting up of all the technological resources required for their enactment. METIS builds on the body of research on learning design $[1,2]$ that has been accumulated during the last decade, as well as on the myriad of available free and open learning design authoring tools that cover a broad range of design practices and pedagogical approaches. The ultimate METIS 
goal is to foster the adoption of learning design practices and tools in real educational practice, without disrupting the current technology-enhanced learning ecosystem, mainly dominated by Virtual Learning Environments (VLEs) and Web 2.0 tools. Thus, METIS's main intended outcomes are: an Integrated Learning Design Environment (ILDE) that enables teachers to choose among multiple learning design authoring tools, (co-)produce, explore, share, evaluate and implement [3] learning designs in mainstream VLEs (e.g., Moodle); and, a set of professional development (PD) actions (e.g., workshops) customized for different educational levels. Such PD actions are aimed at training educators in the use of learning design practices supported by the ILDE, and are also proposed as an instrument to eventually become part of the training programmes of educational institutions. METIS emphasizes the role of community/social aspects as change drivers in teaching practice [4].

This paper describes the current ILDE version (section 2), which has already been employed for supporting several PD actions on learning design (section 3 ).

\section{ILDE: Integrated Learning Design Environment}

The ILDE supports cooperation within "learning design" communities in which their members share and co-create multiple types of learning design solutions covering the complete lifecycle. This has been achieved by the integration of a number of existing learning design tools (Fig. 1), supporting:

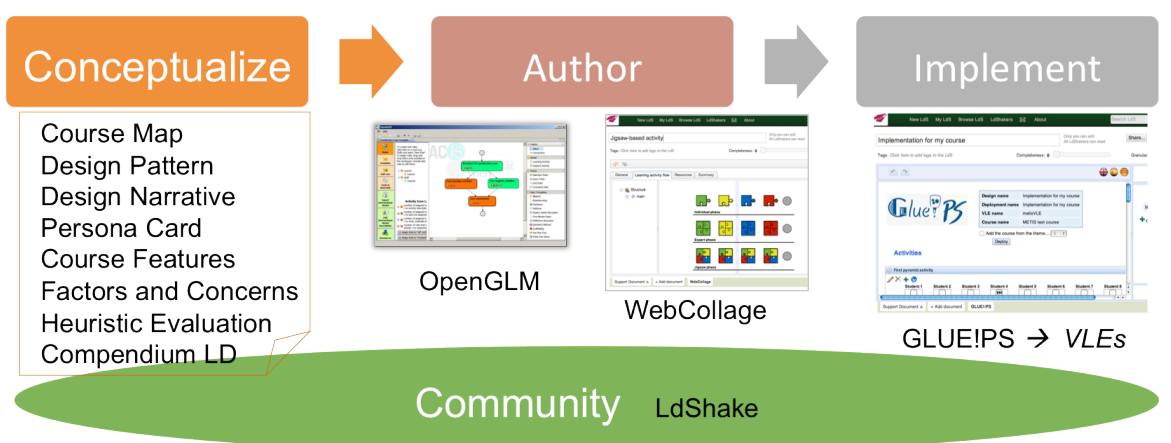

Fig. 1. Schema of tools integrated in the ILDE

Community: To support co-design, sharing, self- and peer-review evaluation of learning design solutions the ILDE is built on top of LdShake [4]. LdShake provides social network features, including sharing designs with different access rights, public comments to designs, private messages, exploration of shared designs, exploration of community members' activity, etc. Thus, it also acts as a repository, controls the access to designs, and embeds in its web space conceptualization, authoring and implementation tools; all in all, offering an integrated user experience.

Conceptualization: Before starting with the actual creation of learning designs, it is important to reflect about the characteristics of the context in which the designs will be applied (e.g., Personas, Factors and Concerns), sketch ideas for the design (e.g., Course Features, Course Map) and reflect about abstract descriptions (e.g., Design 
Pattern, Design Narrative). The ILDE integrates a number of design templates and tools facilitating the conceptualization of learning design solutions, most of them derived from the OULDI project [5].

Authoring: Authoring is the key step between the often sketchy conceptualization of a learning design solution and the implementation of the learning design solution in VLEs that provide the runtime environment for the design artefacts. This requires the production of a detailed definition of a learning design that can be deployed and executed with a specific group of learners. There are several tools available for this learning design stage. Most of the tools allow visual authoring of learning designs, yet each tool provides its own authoring approach. For instance, WebCollage [6] allows learning design modelling in the web browser based on design patterns; being a webbased application, WebCollage is directly integrated within ILDE's workflow. OpenGLM [7], on the other hand, is a desktop application that can produce learning designs in a format understood by the ILDE, which can be used for implementation of such detailed designs. To integrate with the ILDE, OpenGLM offers search in, import from, and export to ILDE within its desktop user interface. Similarly, CADMOS [8], being currently integrated in ILDE, separates the structural-conceptual perspective on learning design (e.g. activities) and the flow perspective. Generally, ILDE allows the attachment of arbitrary file types to the design solutions, some of which can be used further for implementation - e.g., IMS Learning Design [9] compliant packages.

Implementation: This phase includes a first step in which an authored learning design is particularized for a concrete learning situation, e.g., a "course" in a specific VLE. It involves creating groups with the students enrolled in the VLE, assigning groups to different learning activities, and selecting learning tools to support those activities (both tools provided by the VLE itself, or external third-party web 2.0 tools that are integrated in the VLE using the GLUE! system [10]). For carrying out this particularization of the designs, the ILDE makes use of the GLUE!-PS system [11]. GLUE!-PS translates learning designs, represented with the computational languages of the different authoring tools, into a common internal representation or "lingua franca". The teachers, using the GLUE!-PS graphical user interface, then manipulate these representations. In a second step, once all the details of the particularized design are worked out, GLUE!-PS "deploys" it into the VLE, i.e. it sets up and configures all the VLE elements that represent the learning design (activities, groups, tools, ...). Thus, for instance, a WebCollage authored learning design can be automatically transformed into a Moodle course ready to be accessed by the participating students.

\section{Pilots using the ILDE}

The ILDE has been employed in the support of several PD actions in institutions for Vocational Training, Adult Education and Higher Education. Part of the PD actions consisted of "collaborative learning (CL) training workshops" in which participants were instructed about CL fundamentals, practised in co-conceptualizing and co-authoring CL activities, and were finally guided through the process of deploying their designs into Moodle. All workshop activities were carried out with the support of the ILDE, including the sharing and peer-evaluation of the designs. A 
second subset of PD actions included the enactment of a selection of the designs with students in authentic conditions. These enactments close the cycle of going from pedagogical ideas to their actual use with students, with the support of the ILDE. A total of 48 teachers were involved in a first round of workshops (12/2013-4/2014). A second round of workshops is planned for the second half of 2014.

Demonstration outline. The main ILDE features and affordances (as described in section 3) will be demonstrated at the conference. A video of the ILDE and links to the different installations used in the workshops (mentioned in section 4) are available at http://ilde.upf.edu/about/

Acknowledgments. This work has been partially funded by EACEA, METIS Project 531262-LLP-2012-ES-KA3-KA3MP and the Spanish EEE project (TIN2011-28308C03-03). The authors acknowledge the contributions from other project members, including the technical assistants: Pablo Abenia, Javier Hoyos and Rizwan Uppal.

\section{References}

1. Conole, G.: Designing for Learning in an Open World. Springer, Heidelberg (2012)

2. Mor, Y., Craft, B., Hernández-Leo, D.: The Art and Science of Learning Design. Research in Learning Technology Supplement, 21, 22513 (2013)

3. Hernández-Leo, D., Chacón, J., Prieto, L.P., Asensio-Pérez, J.I., Derntl, M.: Towards and Integrated Learning Design Environment. In: 8th European Conf. Technology-Enhanced Learning, LNCS vol. 8095, pp. 448-453, Springer, Heidelberg (2013)

4. Hernández-Leo, D., Romeo, L., Carralero, M.A., Chacón, J., Carrió, M., Moreno, P., Blat, J.: LdShake: Learning design solutions sharing and co-edition. Computers \& Education, 57(4), 2249-2260 (2011)

5. Cross, S., Galley, R., Brasher, A., Weller, M.: OULDI-JISC project evaluation report: The impact of new curriculum design tools and approaches on institutional process and design cultures. OULDI Project, at http://oro.open.ac.uk/34140/ (2012)

6. Villasclaras-Fernández, E. D., Hernández-Leo, D., Asensio-Pérez, J. I., Dimitriadis, Y.: Web Collage: an implementation of support for assessment design in CSCL macro-scripts. Computers \& Education, 67, 79-97 (2013)

7. Derntl, M., Neumann, S., \& Oberhuemer, P.: Propelling standards-based sharing and reuse in instructional modeling communities: The open graphical learning modeler (OpenGLM). In: 11th Int. Conf. Advanced Learning Technologies, pp. 431-435. IEEE Press, NY (2011)

8. Katsamani, M., Retalis, S.: Designing a Moodle course with the CADMOS learning design tool. Educational Media International, 49 (2012) 317-331.

9. IMS Global: Learning Design. Available at http://imsglobal.org/learningdesign (2003)

10. Alario-Hoyos, C., Bote-Lorenzo, M.L., Gómez-Sánchez, E., Asensio-Pérez, J.I., VegaGorgojo, G., Ruiz-Calleja, A.: GLUE!: an architecture for the integration of external tools in virtual learning environments. Computers \& Education, 60(1), 122-137 (2013)

11. Prieto, L.P., Asensio-Pérez, J.I., Muñoz-Cristóbal, J.A., Dimitriadis, Y., Jorrín-Abellán, I.M., Gómez-Sánchez, E.: Enabling Teachers to Deploy CSCL Designs across Distributed Learning Environments. IEEE Transactions on Learning Technologies, 6(4), 324-336 (2013) 